\title{
Liquid Crystalline Polymers for Efficient Bilayer-Bulk-Heterojunction Solar Cells
}

\author{
Qingjiang Sun, Kyusoon Park, and Liming Dai* \\ Department of Chemical and Materials Engineering, School of Engineering, University of Dayton, \\ Dayton, Ohio 45469
}

Received: January 9, 2009; Revised Manuscript Received: March 9, 2009

\begin{abstract}
The unique temperature-dependent solubility of liquid crystalline poly(2,5-bis(3-alkylthiophen-2-yl)thieno[3,2$b$ ] thiophene) (PBTTT) enabled us to construct the first bilayer-bulk-heterojunction devices based on a PBTTT: PCBM (1:2)/MDMO-PPV:[70]PCBM (1:4) active layer. The bilayer device exhibited an extended optical absorption over the solar spectrum and concentration gradient that enhanced charge carrier transport. Postannealing the bilayer-bulk-heterojunction devices yielded a $V_{\mathrm{oc}}$ of $0.59 \mathrm{~V}, J_{\mathrm{sc}}$ values of 10.1-10.7 mA/ $\mathrm{cm}^{2}$, an FF of 0.50 , and PCE values of 3.0-3.2\%, showing an increased $J_{\mathrm{sc}}$ and PCE by a factor of 2 with respect to their single layer counterparts. This study suggests that the bilayered device structure has distinct advantages for the development of highly efficient polymer solar cells.
\end{abstract}

\section{Introduction}

The increasing demands for inexpensive renewable energy sources have stimulated extensive research activities to develop low-cost and highly efficient photovoltaic devices, particularly polymer solar cells. ${ }^{1-3}$ The photovoltaic effect in a polymer solar cell involves the generation of electron-hole pairs (i.e., excitons) in the donor (polymer) phase under illumination, followed by subsequent charge separation and collection at opposite electrodes. Dissociation of the excitons (i.e., charge separation) occurs only at the heterojunction interface between semiconducting materials of different ionization potentials or electron affinities. Bulk-heterojunction solar cells with the polymer donor and acceptor mixing at the molecular level to maximize the interfacial area for charge separation have thus been considered to be ideal photovoltaic devices. ${ }^{4}$ Typical donor-type polymers include derivatives of poly( $p$-phenylene vinylene) and polythiophene, such as poly[2-methoxy-5-(3,7-dimethyloctyloxy)]1,4-phenylenevinylene) (MDMO-PPV) ${ }^{5}$ and regioregular poly(3hexylthiophene) (P3HT), ${ }^{6-8}$ while a soluble $\mathrm{C}_{60}$ derivative (i.e., 1-(3-methoxycarbonal)propyl-1-phenyl[6,6]C61, PCBM) has been widely used as the acceptor. ${ }^{9}$

In a bulk-heterojunction, the efficiency of charge transfer from donor to acceptor can be unity as the donor-acceptor are often phase separated at the length scale within the exciton diffusion length $(10-20 \mathrm{~nm}){ }^{1,4}$ Therefore, it is of paramount importance to increase the exciton creation. For this purpose, many innovative synthetic routes have been devised to produce various low band gap polymers, such as donor- $\pi$-acceptor conjugated polymers ${ }^{10,11}$ and polythiophenes grafted with appropriate side chains ${ }^{12}$ or copolymerized with fluorene moieties, ${ }^{13}$ for harvesting solar photons. Recent studies have shown that the hole transport is also important to highly efficient bulk-heterojunction polymer solar cells. For instance, the higher hole mobility of $0.05-0.1 \mathrm{~cm}^{2} / \mathrm{V}$ s for $\mathrm{P}^{1} \mathrm{HT}^{14,15}$ than that for MDMO-PPV $\left(\sim 10^{-4} \mathrm{~cm}^{2} / \mathrm{V} \mathrm{s}\right)^{16}$ has led to the higher reported power conversion efficiency (PCE, up to $5 \%)^{8}$ for the former than that for the latter $(\mathrm{PCE}=2.5 \%)^{5}$ in their bulk-heterojunction solar cells with PCBM as the electron donor. The high efficiency of

* To whom correspondence should be addressed. E-mail: 1dai@udayton.edu.
P3HT-based solar cells arises from the postannealing-induced formation of a microcrystalline lamellar stacking of P3HT in the solid state ${ }^{17,18}$ to facilitate hole transport and reduce charge recombination. MDMO-PPV and P3HT are amorphous and semicrystalline, respectively, both exhibiting a significant amount of kinetically trapped disorders in the solid state film. It is necessary to increase the mesoscopic order and crystallinity for these polymers in order to enhance the efficiency of charge carrier transport. In this context, a new class of polythiophene derivatives, including poly(2,5-bis(3-alkylthiophen-2-yl)thieno[3,2$b$ ]thiophene) (PBTTT), ${ }^{19}$ has recently been synthesized to contain chemical moieties with strong $\pi-\pi$ intermolecular interactions for close packing of the macromolecule chains into large crystalline domains upon crystallization from a liquidcrystal phase. ${ }^{20-22}$ Due to the increased structure order and crystallinity, thin-film transistors made from PBTTT have been demonstrated to exhibit a hole mobility of $0.2-0.6 \mathrm{~cm}^{2} / \mathrm{V} \mathrm{s},{ }^{23-26}$ which is higher than that of P3HT and is compared favorably to that of amorphous silicon. However, the use of such a highmobility semiconducting polymer in bulk-heterojunction solar cells, though very promising, hardly has been investigated while its use in a single-layer bulk-heterojunction solar cell was briefly discussed in a recent paper. ${ }^{27}$ Here, we report our study on bilayer-bulk-heterojunction solar cells, involving a PBTTT/ PCBM active layer. The use of the bilayer structure is to introduce the concentration gradient of charge carriers to reduce the loss by recombination as charge carrier transport is a competitive process with charge recombination in a polymer bulk-heterojunction solar cell. The bilayer structure can also enhance light harvesting by covering the optical absorption for each of the constituent layers. Although concentration gradients can be created in bilayer and even multilayer devices by selective evaporation, ${ }^{28-30}$ it is not always easy to prepare polymer solar cells with a multilayer structure by solutioncasting due to solubility mismatching.

PBTTT liquid crystalline polymers exhibit an interesting solubility in 1,2-dichrorobenzene (DCB) or chrorobenzene (CB) - high solubility at a relatively high temperature but insoluble at room temperature. This unique temperaturedependent solubility of PBTTT enabled us to spin-coat a DCB solution of PBTTT at $70{ }^{\circ} \mathrm{C}$ and another overlaid polymer (e.g., 
MDMO-PPV) from the same solvent at room temperature without dissolving the preformed underlying PBTTT layer. As a result, the fabrication of single-layer and bilayer-bulkheterojunction solar cells from the PBTTT of a high hole mobility by an all-solution process was achieved. Large crystalline domains formed even within a PBTTT:PCBM blend upon postannealing. Solar cells with a PBTTT:PCBM (1:2 w/w)/ MDMO-PPV:[70] PCBM (1:4 w/w) bilayer structure showed remarkably enhanced solar absorption and charge transport efficiencies. Both the short circuit current $\left(J_{s c}\right)$ and PCE of the bilayer solar cells were found to increase by a factor of up to about two with respect to their single-layer counterparts, indicating that the bilayer structure has a distinct advantage.

\section{Experimental Sections}

Materials. Indium - tin oxide (ITO) glass was purchased from Delta Technologies Limited while PEDOT:PSS (Baytron P Al4083) was obtained from Bayer Inc. PBTTT and P3HT were purchased from EMD Chemicals (Merck), Inc., and Rieke Metals, Inc., respectively. [60]PCBM was supplied by NanoC, Inc. MDMO-PPV, and [70]PCBM and $\mathrm{Al}(99.999 \%)$ were purchased from Aldrich Chemicals, Inc. The $\mathrm{TiO}_{x}$ precursor solution was prepared according to the published procedure, ${ }^{8}$ and was diluted by 1:10 in ethanol for spin-coating.

Characterizations. UV/visible absorption of dilute solutions $(0.1 \mathrm{mg} / \mathrm{mL})$ and thin films $(\sim 100 \mathrm{~nm})$ of PBTTT, P3HT, and MDMO-PPV was measured on a PerkinElmer Lambda 900 UV/ vis/NIR spectrometer. The cyclic voltammetry was performed on a $\mathrm{CH} 760$ potentiostat, in an acetonitrile solution of $0.1 \mathrm{~mol} / \mathrm{L}$ of $\left[\mathrm{Bu}_{4} \mathrm{~N}\right] \mathrm{PF}_{6}$ at a potential sweep rate of $0.05 \mathrm{~V} / \mathrm{s}$ at room temperature under the protection of dry $\mathrm{N}_{2}$. A glassy carbon electrode coated with a thin film of either PBTTT or P3HT was used as the working electrode. A Pt wire and an $\mathrm{Ag}$ wire were used as the counter electrode and quasireference electrode, respectively. The electrochemical potential was calibrated against $\mathrm{Fc} / \mathrm{Fc}^{+}$. Differential scanning calorimetry (DSC) of PBTTT was measured with a TA Instrument DSC Q100 at a heating rate of $10 \mathrm{deg} / \mathrm{min}$ under $\mathrm{N}_{2}$ atmosphere.

Device Fabrication and Characterization. ITO was used as the anode and $\mathrm{Al}$ thermally deposited under vacuum $\left(<10^{-6}\right.$ Torr) was used as the cathode. Before device fabrication, the glass substrates coated with prepatterned ITO $(\sim 180 \mathrm{~nm})$ were cleaned sequentially by ultrasonic treatment in dilute MICRO90 detergent, deionized water, acetone, isopropyl alcohol, and UV-ozone treatment for $20 \mathrm{~min}$. A 30-nm-thick buffer layer of poly(3,4-ethylenedioxythiophene):poly(styrene sulfonate) (PEDOT:PSS) was spin-coated from an aqueous solution onto the ITO coated glass substrates, followed by baking at $150{ }^{\circ} \mathrm{C}$ for $15 \mathrm{~min}$.

For single-layer bulk-heterojunction devices, a PBTTT and PCBM mixture was prepared by codissolving PBTTT $(20 \mathrm{mg})$ and PCBM in $1 \mathrm{~mL}$ of DCB at $70{ }^{\circ} \mathrm{C}$ with PBTTT/PCBM weight ratios of 1:0.5, 1:1, 1:1.5, 1:2, 1:3, and 1:4. PBTTT: PCBM blend films $(80-150 \mathrm{~nm})$ were prepared by spin-coating a warm solution on the top of ITO/PEDOT $\left(50{ }^{\circ} \mathrm{C}\right)$, followed by thermal annealing at $85{ }^{\circ} \mathrm{C}$ for $0.5 \mathrm{~h}$. For bilayer-bulkheterojunction devices, PBTTT:PCBM solutions were prepared by codissolving PBTTT $(20 \mathrm{mg})$ and PCBM $(40 \mathrm{mg})$ in $1 \mathrm{~mL}$ of DCB at $70{ }^{\circ} \mathrm{C}$. The MDMO-PPV:[70]PCBM solutions were prepared by codissolving MDMO-PPV $(10 \mathrm{mg})$ and [70]PCBM $(40 \mathrm{mg})$ in $1 \mathrm{~mL}$ of chlorobenzene at room temperature. The PBTTT:PCBM layer $(60 \mathrm{~nm})$ was prepared by spin-coating the warm solution on the top of ITO/PEDOT, followed by an annealing treatment at $85{ }^{\circ} \mathrm{C}$ for $1 \mathrm{~h}$. The MDMO-PPV:

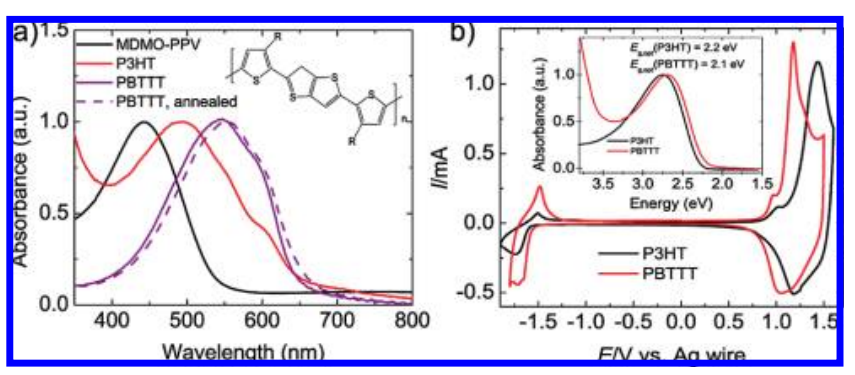

Figure 1. (a) Optical absorption of thin films $(\sim 60 \mathrm{~nm})$ of MDMOPPV, P3HT, and PBTTT before and after annealing at $120{ }^{\circ} \mathrm{C}$ for 4 min, followed by cooling to room temperature at a cooling speed of 1 $\mathrm{deg} / \mathrm{min}$. The inset shows the molecular structure of PBTTT $(\mathrm{R}=$ $\mathrm{C}_{21} \mathrm{H}_{43}$ ). (b) Cyclic voltammograms of P3HT and PBTTT thin films on glassy carbon electrode in an acetonitrile solution of $0.1 \mathrm{~mol} / \mathrm{L}$ of $\left[\mathrm{Bu}_{4} \mathrm{~N}\right] \mathrm{PF}_{6}$ at room temperature under the protection of dry $\mathrm{N}_{2}$.

[70]PCBM layer $(90 \mathrm{~nm})$ was then spin-coated on the top of the PBTTT:PCBM layer, followed by annealing at $80^{\circ} \mathrm{C}$ for $0.5 \mathrm{~h}$. If necessary, the $\mathrm{TiO}_{x}$ precursor solution was spin-coated $(6000 \mathrm{rpm} / \mathrm{min})$ in air on the top of the PBTTT:PCBM layer for single-layer bulk-heterojunction devices, and on the top of the MDMO-PPV:[70]PCBM layer for bilayer-bulk-heterojunction devices. Subsequent heating of the samples in air at $80^{\circ} \mathrm{C}$ for $20 \mathrm{~min}$ converted the precursor into $\mathrm{TiO}_{x}(\sim 20 \mathrm{~nm})$ via hydrolysis. The thicknesses of all the films were measured by a Dektak profiler. Postannealing of some devices was conducted by heating at $120{ }^{\circ} \mathrm{C}$ for $4 \mathrm{~min}$, followed by cooling to room temperature at a cooling speed of $1 \mathrm{deg} / \mathrm{min}$.

The current-voltage $(I-V)$ curves were recorded on a Keithly 236 source-measurement unit. The photocurrent was measured under simulated AM1.5G irradiation $\left(100 \mathrm{~mW} / \mathrm{cm}^{2}\right)$, using a xenon lamp-based solar simulator (XPS-400, Solar Light Co.). The fill factor (FF) was calculated by $\mathrm{FF}=\left(V_{\max } J_{\max }\right) /\left(J_{\mathrm{sc}} V_{\mathrm{oc}}\right)$, where $V_{\max }$ and $J_{\max }$ are the voltage and the current density in the maximum power point of the $I-V$ curve in the fourth quadrant. The normal power conversion efficiency was calculated from the expression

$$
\mathrm{PCE}=\mathrm{FF} \times I_{\mathrm{sc}}\left(\mathrm{mA} / \mathrm{cm}^{2}\right) \times V_{\mathrm{oc}}(\mathrm{V}) / P_{\text {in }}\left(\mathrm{mW} / \mathrm{cm}^{2}\right)
$$

where $V_{\mathrm{oc}}, I_{\mathrm{sc}}, \mathrm{FF}$, and $P_{\text {in }}$ are the open circuit voltage, short circuit current, fill factor, and incident light power, respectively. All devices were fabricated and tested in oxygen and moisturefree nitrogen environment inside a glovebox $\left(<0.3 \mathrm{ppm} \mathrm{O}_{2}\right.$ and $\mathrm{H}_{2} \mathrm{O}$ ).

\section{Results and Discussion}

The molecular structure of the particular PBTTT sample used in this study is given in the inset of Figure 1a. As can be seen, each monomer unit comprises two thiophene rings and one fused ring with two alkyl side chains $\left(\mathrm{R}=\mathrm{C}_{21} \mathrm{H}_{43}\right)$ attached onto the neighboring thiophene rings in a tail-to-tail configuration. The rotational invariance of the two symmetrically fused thiophene rings in the polymer backbone facilitates the adoption of a lowenergy backbone conformation favorable for the formation of highly ordered crystalline domains. ${ }^{19}$ On the other hand, the tail-to-tail arrangement of the alkyl side chains can promote self-organization and minimize steric interactions, if any, between the neighboring alkyl groups for a backbone planarity. These structural features make PBTTT attractive for highefficient solar cell applications.

Figure 1a shows the UV-visible absorption of the solutioncast thin films $(\sim 60 \mathrm{~nm})$ of MDMO-PPV, P3HT, and PBTTT, respectively. Also included is the corresponding PBTTT film 


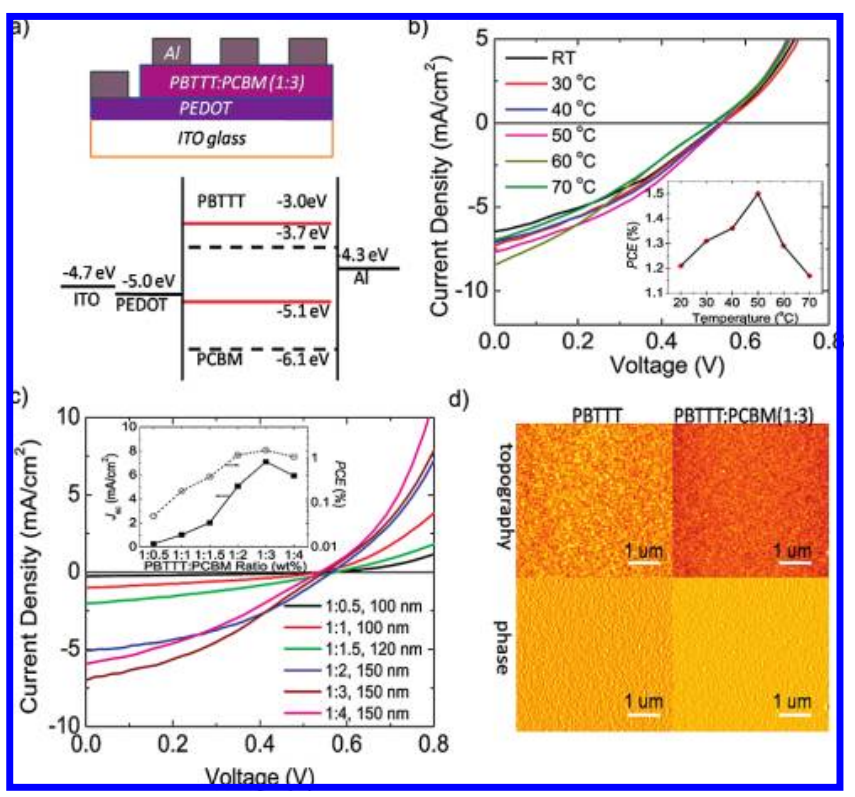

Figure 2. (a) A schematic representation of the device configuration (up) of a bulk-heterojunction solar cell based on PBTTT:PCBM (1:3 wt \%), and the associated energy level diagram (bottom). (b) $J-V$ characteristics of the ITO/PEDOT/PBTTT:PCBM (1:3 wt \%)/Al solar cells at different substrate temperatures. The inset shows the PCE values as a function of the substrate temperature. (c) $J-V$ characteristics of the ITO/PEDOT/PBTTT:PCBM/Al solar cells with different weight ratios of PBTTT to PCBM at the substrate temperature of $50{ }^{\circ} \mathrm{C}$. The inset shows the $J_{\mathrm{sc}}$ and PCE values of the devices as a function of the PBTTT:PCBM weight ratio. (d) Topographical (up) and phase (bottom) AFM images of pure PBTTT films and PBTTT:PCBM (1:3 wt \%) films on the ITO/PEDOT substrate.

after thermal annealing (dot curve, vide supra). As can be seen, the absorption of the PBTTT thin film onsets at $\sim 650 \mathrm{~nm}(1.9$ $\mathrm{eV})$ with a peak at $\sim 550 \mathrm{~nm}(2.3 \mathrm{eV})$. Compared to those of MDMO-PPV ( $\sim 40 \mathrm{~nm})$ and P3HT ( $500 \mathrm{~nm})$, the maximum absorption of PBTTT is approximately 110 and $50 \mathrm{~nm}$ redshifted, respectively. These spectroscopic differences clearly indicate an enhanced absorption to the solar spectrum for PBTTT, since the maximum photon flux of the solar spectrum is at $\sim 700 \mathrm{~nm}(1.8 \mathrm{eV})$.

Electrochemical cyclic voltammetry was performed to determine the highest occupied molecular orbital (HOMO) and lowest unoccupied molecular orbital (LUMO) levels of PBTTT. Figure 1b shows a cyclic voltammogram of a PBTTT thin film. For comparison, the corresponding cyclic voltammogram of $\mathrm{P} 3 \mathrm{HT}$ is also given in Figure 1b. Reversible oxidation and reduction processes were observed for both PBTTT and P3HT, which are typical for polythiophene derivatives. The onset potential for oxidations $\left(E_{\mathrm{ox}}{ }^{\prime}\right)$ of both PBTTT and P3HT is ca. $0.72 \mathrm{~V}$ vs. Ag wire while the onset potential for reduction $\left(E_{\text {red }}{ }^{\prime}\right)$ of PBTTT is ca. $-1.44 \mathrm{~V}$ vs. Ag wire that is $\sim 0.1 \mathrm{eV}$ higher than that of P3HT. The HOMOs of PBTTT and P3HT are then calculated to be -5.1 $\mathrm{eV}$, and the LUMOs of PBTTT and P3HT are -3.0 and $-2.9 \mathrm{eV}$, respectively. ${ }^{31}$ The electrochemically determined band gaps for PBTTT (2.1 eV) and P3HT (2.2 eV) are consistent with the corresponding optical energy gaps estimated from the onset absorption of the two polymers in dilute solutions (see the inset of Figure 1b). There is an about $20 \mathrm{~nm}$ red-shift in the solution absorption maximum (and onset) for PBTTT compared to P3HT in solution due to the presence of the highly delocalized thienothiophene aromatic rings in the PBTTT backbone.

Figure 2a shows a schematic representation of a single-layer bulk-heterojunction solar cell based on a blend film of PBTTT:
PCBM (1:3 w/w). A spin-coated poly(3,4-ethylenedioxythiophene):poly(styrenesulfonate) (PEDOT:PSS) thin film on the top of the ITO substrate acts as a buffer layer. The PBTTT/ PCBM blend film was prepared by spin-coating a mixture of codissolved PBTTT $(20 \mathrm{mg})$ and PCBM $(60 \mathrm{mg})$ in $1 \mathrm{~mL}$ of $\mathrm{DCB}$ at $70{ }^{\circ} \mathrm{C}$ on the top surface of the ITO/PEDOT layer, followed by annealing at $80{ }^{\circ} \mathrm{C}$ for $30 \mathrm{~min}$. The energy-level diagram for the materials involved in the single-layer photovoltaic device is also given in Figure 2a. Since the HOMO and LUMO of PBTTT are 1.0 and $0.7 \mathrm{eV}$ higher than the corresponding energy levels of PCBM, PBTTT and PCBM act as a donor and an acceptor, respectively. The HOMO and LUMO of PBTTT match well with work functions of the anode and cathode, respectively, for both the hole and electron conductions.

In view of the importance of the interface morphology to thin film devices, including field effect transistors (FETs) ${ }^{32}$ and solar cells, 5,18,28 we investigated temperature effects on the performance for solar cells prepared by spin-casting PBTTT/ PCBM $(1: 3 \mathrm{w} / \mathrm{w})$ onto the ITO/PEDOT substrates at different temperatures over $20-70{ }^{\circ} \mathrm{C}$. Current density-voltage $(J-V)$ characteristics at different temperatures are shown in Figure 2b, along with the corresponding temperature-dependent PEC curve (inset of Figure 2b). As can be seen, the substrate temperature affected mainly the short circuit current density $\left(J_{\text {sc }}\right)$ with the open circuit voltage $\left(V_{\text {oc }}\right)$ remaining largely unchanged. As a consequence, the PCE continuously increased from $1.2 \%$ to $1.5 \%$ with an increase in the substrate temperature from room temperature $\left(20^{\circ} \mathrm{C}\right)$ to $50^{\circ} \mathrm{C}$. Since PBTTT was spin-cast from a warm DCB solution $\left(70{ }^{\circ} \mathrm{C}\right)$, it could crystallize quickly with defects upon contacting the substrate at lower temperatures. However, PBTTT macromolecules in the bulk volume could take a long time to crystallize during the slow film formation as the boiling point of DCB is as high as $180{ }^{\circ} \mathrm{C}$. The defectrich PBTTT crystalline domains at the interface with the PEDOT layer may act as trap sites to reduce the overall hole mobility of PBTTT across the photovoltaic active film. The decrease in the hole collection efficiency induced by the interfacial defects is proportional to the decrease in the substrate temperature. The observed decrease in PEC above $50{ }^{\circ} \mathrm{C}$ (inset of Figure 2b) is probably due to the relatively faster evaporation of DCB, which, in turn, led to fast crystallization of PBTTT with defects even introduced into the bulk film. Therefore, the optimized ITO/ PEDOT substrate temperature for spin-coating PBTTT:PCBM from a warm $\mathrm{DCB}$ solution $\left(70{ }^{\circ} \mathrm{C}\right)$ seemed to be $50{ }^{\circ} \mathrm{C}$. All devices described thereafter have thus been fabricated on the ITO/PEDOT substrates at $50{ }^{\circ} \mathrm{C}$. The optimized photovoltaic device shown in Figure 2a exhibited a $J_{\mathrm{sc}}$ of $7.3 \mathrm{~mA} / \mathrm{cm}^{2}$, a $V_{\mathrm{oc}}$ of $0.57 \mathrm{~V}$, and a fill factor (FF) of 0.36 .

Having established the optimized conditions for the device fabrication, we further investigated bulk-heterojunction solar cells based on single-layer PBTTT:PCBM blends with different weight ratios of $1: 0.5,1: 1,1: 1.5,1: 2,1: 3$, to $1: 4$. The measured $J-V$ curves given in Figure 2c show a strong dependence of the device performance on the PBTTT:PCBM weight ratios. The device with a 1:3 weight ratio of PBTTT to PCBM showed the best performance with a PCE about 30 times that of its counterpart with a PBTTT:PCBM weight ratio of 1:0.5. The observed increase in PCE with increasing PBTTT:PCBM ratio results from an enhanced electron mobility associated with an increased PCBM content within the blend film. ${ }^{33}$ Figure $2 \mathrm{~d}$ shows the atomic force microscopy (AFM) images for thin films of pure PBTTT and PBTTT:PCBM (1:3 w/w). Similar to the pure PBTTT, the PBTTT:PCBM blend film showed a uniform 


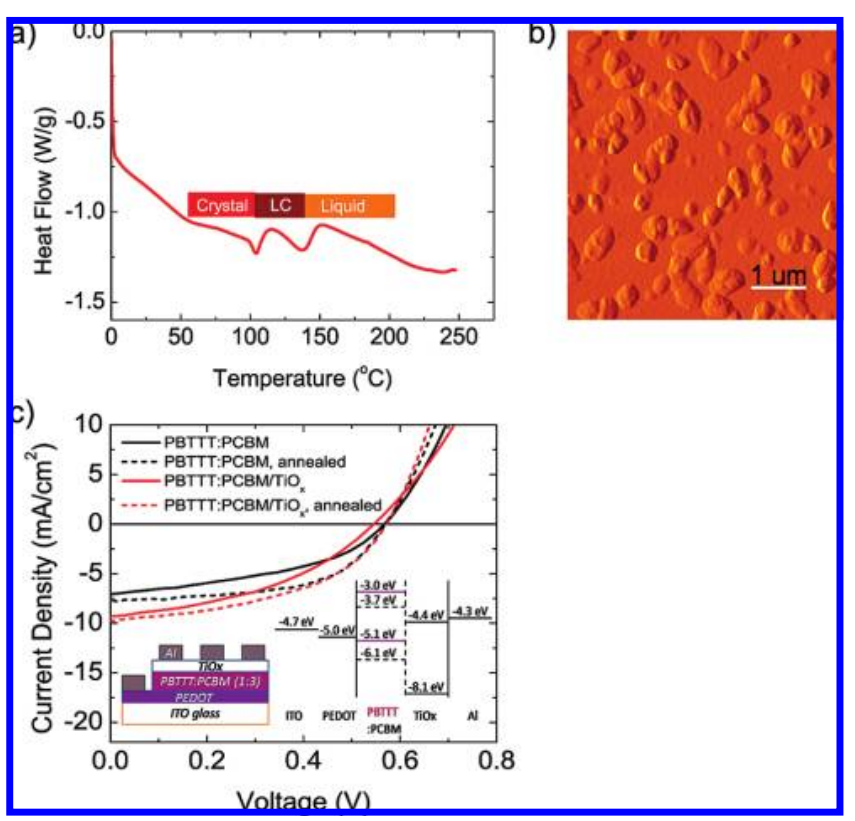

Figure 3. (a) Differential scanning calorimetry of PBTTT at a heating rate of $10 \mathrm{deg} / \mathrm{min}$ under $\mathrm{N}_{2}$ atmosphere. (b) An AFM phase image of a PBTTT:PCBM $(1: 3 \mathrm{wt} \%)$ blend film after being annealed at $120^{\circ} \mathrm{C}$ for $4 \mathrm{~min}$, followed by cooling to room temperature at a cooling speed of $1 \mathrm{deg} / \mathrm{min}$. (c) $J-V$ characteristics of the as-prepared and postannealed PBTTT:PCBM (1:3 wt \%) solar cells with and without $\mathrm{TiO}_{x}$. The insets show a schematic device configuration (left) of the PBTTT: $\operatorname{PCBM}(1: 3 \mathrm{wt} \%)$ solar cell with $\mathrm{TiO}_{x}$ and the associated energy level diagram (right).

and pinhole free surface (the rms roughness is less than $1 \mathrm{~nm}$ ). The decreased PCE observed at a PBTTT:PCBM weight ratio of 1:4 is, most probably, due to the over suppressed hole transport induced by the relatively reduced nanoscale clusters of PBTTT in the active layer and/or increased PCBM trap sites for charge combination. The diluted solar absorption associated with the relatively reduced amount of PBTTT in the active layer may also contribute to the reduced PCE to a certain extent. Consequently, the 1:3 weight ratio for PBTTT to PCBM was chosen as the optimized value for subsequent investigations in this study.

To further enhance the device performance, we performed the postannealing study. Previous work has demonstrated that the thermal annealing liquid crystalline mesophase of pure PBTTT can increase the size of crystalline domains in the polymer film to facilitate the hole transport. ${ }^{19,20}$ Figure $3 \mathrm{a}$ reproduces the differential scanning calorimetry (DSC) curves for PBTTT, which shows two discrete endotherms upon heating with the transition from a crystal phase below $\sim 100{ }^{\circ} \mathrm{C}$ to a liquid phase above $\sim 150{ }^{\circ} \mathrm{C}$, through the liquid-crystal (LC) phase over about $100-140^{\circ} \mathrm{C}$. The AFM image given in Figure $3 \mathrm{~b}$ reveals that annealing a thin film of PBTTT:PCBM $(1: 3 \mathrm{w} / \mathrm{w}$, $150 \mathrm{~nm}$ ) on the top of an ITO/PEDOT substrate up to above $120{ }^{\circ} \mathrm{C}$ caused the morphology change from a module-like nanostructure characteristic of the as-cast PBTTT film (cf. Figure 2d) to an oriented polycrystalline microstructure, which is rather unique among the semiconducting polymers. The large size of PBTTT crystalline domains (ca. submicrons) thus formed are assembled with several smaller sized crystalline domains of reoriented PBTTT chains in the LC phase upon crystallization. Compared with the as-cast PBTTT film, an about 20-nm redshift was observed for the thermally annealed PBTTT film with crystalline domains (cf. Figure 1a).

Figure $3 \mathrm{c}$ shows the $J-V$ curves for the PBTTT:PCBM solar cells before and after being annealed at $80{ }^{\circ} \mathrm{C}$ for $30 \mathrm{~min}$. The

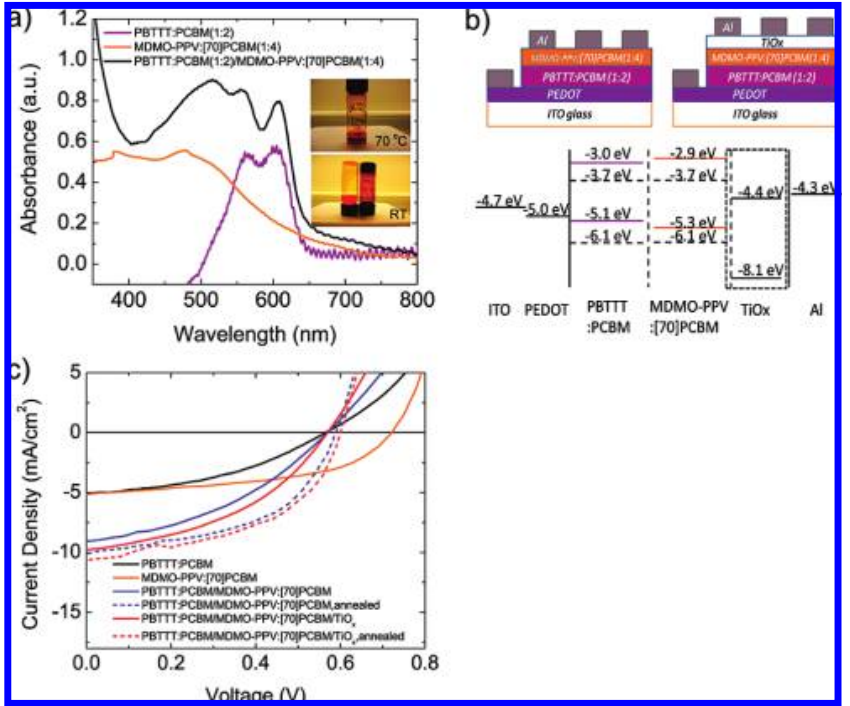

Figure 4. (a) Optical absorption spectra for the blend films of PBTTT: PCBM (1:2 wt \%) and MDMO-PPV:[70]PCBM (1:4 wt \%) and the bilayer blend film of PBTTT:PCBM (1:2 wt \%)/MDMO-PPV: [70]PCBM (1:4 wt \%). The insets show the digital photographs of PBTTT in CB at $70{ }^{\circ} \mathrm{C}$ (up) and PBTTT and MDMO-PPV in CB at room temperature (bottom). (b) Schematic device configurations (up) of the bilayer-bulk-heterojunction solar cell with and without $\mathrm{TiO}_{x}$, and the associated energy level diagram (bottom). (c) $J-V$ characteristics of the single-layer and bilayer bulk-heterojunction solar cells based on PBTTT:PCBM (1:2 wt \%) and MDMO-PPV:[70]PCBM (1:4 wt \%) with and without $\mathrm{TiO}_{x}$ before and after postannealing.

$V_{\text {oc }}$ of the ITO/PEDOT/PBTTT:PCBM (1:3)/Al solar cell remained unchanged while its $J_{\mathrm{sc}}$ slightly increased and the FF significantly increased from 0.36 to 0.55 upon postannealing (vide supra). As a result, the PCE increased from $1.5 \%$ (vide supra) to $2.3 \%$. In a polymer solar cell, the FF is determined by the product of the charge carrier lifetime $\tau$ times the mobility $\mu{ }^{34}$ Therefore, the improved $J_{\mathrm{sc}}$ and FF indicate an enhanced charge carrier transport, attributable to the formation of large PBTTT crystalline domains in the active layer induced by thermal annealing. Given that PBTTT dominates the crystalline domains while PCBM forms mainly the disordered domains for electron transport in the bulk-heterojunction, the postannealing should reduce the free volume and the density of defects at the interface and in the bulk volume of PBTTT to facilitate the hole transport. ${ }^{35}$

In addition to the enhanced hole transport described above, it is essential to also improve the electron transport in order to optimize the device performance. In this context, the incorporation of a thin film of $\mathrm{TiO}_{x}$ between the active layer and the $\mathrm{Al}$ electrode has been demonstrated to significantly improve the photovoltaic outputs of P3HT:PCBM devices. ${ }^{8}$ This is because $\mathrm{TiO}_{x}$ is a good electron transporting material, with its LUMO $(-4.4 \mathrm{eV})$ lower than that of PCBM $(-3.7 \mathrm{eV})$, and is very close to the work function of $\mathrm{Al}(-4.3 \mathrm{eV})$ (inset of Figure $3 c)$. As such, we have also incorporated a thin $\mathrm{TiO}_{x}$ layer into our PBTTT:PCBM devices. Owing to the enhanced electron transport associated with $\mathrm{TiO}_{x}$, the as-prepared ITO/PEDOT/ PBTTT:PCBM $(1: 3 \mathrm{w} / \mathrm{w}) / \mathrm{TiO}_{x} / \mathrm{Al}$ device showed a relatively good performance with respect to its counterpart without $\mathrm{TiO}_{x}$, exhibiting a $V_{\mathrm{oc}}$ of $0.55 \mathrm{~V}$, a $J_{\mathrm{sc}}$ of $9.3 \mathrm{~mA} / \mathrm{cm}^{2}$, a $\mathrm{FF}$ of 0.41 , and a PCE of $2.1 \%$ (Figure $3 \mathrm{c}$ ). Subsequent postannealing led to further enhanced performance with a $V_{\text {oc }}$ of $0.57 \mathrm{~V}, J_{\mathrm{sc}}$ of $9.9 \mathrm{~mA} / \mathrm{cm}^{2}, \mathrm{FF}$ of 0.47 , and PCE of $2.6 \%$ due, once again, to the formation of polycrystalline domains in the active layer. 
TABLE 1: Photovoltaic Properties of the Single-Layer and Bilayer Bulk-Heterojunction Solar Cells Based on PBTTT:PCBM (1:2 wt \%) and MDMO-PPV:[70]PCBM (1:4 wt \%) with and without $\mathrm{TiO}_{x}$ before and after Postannealing

\begin{tabular}{|c|c|c|c|c|}
\hline compositions of active layer & $V_{\mathrm{oc}}(\mathrm{V})$ & $J_{\mathrm{sc}}\left(\mathrm{mA} / \mathrm{cm}^{2}\right)$ & $\mathrm{FF}$ & PCE $(\%)$ \\
\hline PBTTT:PCBM (1:2 wt \%) & 0.57 & 5.1 & 0.40 & 1.2 \\
\hline MDMO-PPV:[70]PCBM (1:4 wt \%) & 0.73 & 5.2 & 0.49 & 1.9 \\
\hline PBTTT:PCBM (1:2 wt \%)/MDMO-PPV:[70]PCBM (1:4 wt \%) & 0.57 & 9.1 & 0.41 & 2.1 \\
\hline PBTTT:PCBM (1:2)/MDMO-PPV:[70]PCBM (1:4)/TiO $x$ & 0.57 & 9.8 & 0.42 & 2.4 \\
\hline PBTTT:PCBM (1:2)/MDMO-PPV:[70]PCBM (1:4)/TiO ${ }_{x}$-annealed & 0.59 & 10.7 & 0.50 & 3.2 \\
\hline
\end{tabular}

As mentioned earlier, the unique temperature-dependent solubility of PBTTT (cf. Figure 4) could enable us to fabricate bilayer solar cells with enhanced solar absorption and concentration gradients for minimizing the charge recombination. Figure 4a shows the UV/vis absorption of single-layer films of PBTTT:PCBM, MDMO-PPV:[70]PCBM, and a bilayer film of PBTTT:PCBM (1:2)/MDMO-PPV:[70]PCBM (1:4), respectively. Due to the dilute effect associated with the high content of PCBM or [70]PCBM in the polymer layers, PBTTT only absorbs solar photons in the range of ca. 500-650 nm (red curve of Figure 4a) while MDMO-PPV absorbs the solar photons over about 400-500 nm only (yellow curve of Figure 4a, cf. Figure 1a). The bilayer blend film, however, showed a continuous solar absorption spectrum from 400 to $650 \mathrm{~nm}$ (black curve of Figure $4 \mathrm{a}$ ), arising from both polymers with additional absorption extended further over ca. $720 \mathrm{~nm}$ associated to [70]PCBM. ${ }^{36}$ As is schematically shown in Figure 4b, bilayer-bulk-heterojunction solar cells were thus fabricated from these bilayer blend films with and without $\mathrm{TiO}_{x}$. In view of the red-shifted absorption of PBTTT with respect to MDMO-PPV, the thickness of the first layer (i.e., the PBTTT layer) was controlled to be thin $(\sim 60 \mathrm{~nm})$ to allow the incident light to reach the second layer. As the HOMO of PBTTT is $0.2 \mathrm{eV}$ higher than that of MDMO-PPV, holes from the second layer can effectively pass through the first layer to the anode. The donor-acceptor weight ratio is controlled to be 1:2 in the first layer and 1:4 in the second layer to reduce the optical absorption in the first layer and to create the concentration gradient for minimizing charge recombination.

$J-V$ characteristics of the bilayer-bulk-heterojunction devices are shown in Figure $4 \mathrm{c}$ while the numerical photovoltaic parameters are listed in Table 1. Single-layer devices with PBTTT:PCBM and MDMO-PPV:[70]PCBM are also prepared under the identical conditions for references. While both the single PBTTT:PCBM layer and bilayer solar cells exhibited a similar $V_{\text {oc }}$, the as-prepared bilayer device showed a much higher $J_{\text {sc }}$ and PCE. It was further found that the $V_{\text {oc }}$ is closely related to the relative thickness of the constituent layers in the bilayer bulk-heterojunction. Reducing the thickness of the first layer gradually shifted the $V_{\mathrm{oc}}$ of the bilayer solar cell to that of the MDMO-PPV:[70]PCBM device. Typically, the $J_{\mathrm{sc}}$ is determined by the product of the photoinduced charge carrier density and the charge carrier mobility: ${ }^{37} J_{\mathrm{sc}}=n e \mu E$, where $n$ is the charge carrier density, $e$ is the elementary charge, $\mu$ is the mobility, and $E$ is the electric field. The observed high $J_{\text {sc }}$ for the bilayer bulk-heterojunction structure is attributable to the increased $n$ by the extended absorption to solar photons as well as the increased $E$ induced by additional electrical forces related to the concentration gradient of charge carriers across the bilayer bulk-heterojunction. The introduction of an additional $\mathrm{TiO}_{x}$ layer between the active layer and the $\mathrm{Al}$ cathode further increased the $J_{\mathrm{sc}}$ and PCE for the bilayer bulk-heterojunction device. The formation of large polycrystalline domains of PBTTT in the first layer induced by postannealing also increased the photovoltaic outputs for both devices with and without $\mathrm{TiO}_{x}(\mathrm{Table}$ 1).

\section{Conclusions}

In summary, we have fabricated highly-efficient bilayer bulkheterojunction solar cells from high-hole-mobility liquid crystalline polymer (PBTTT). The bilayer structure was demonstrated to show extended optical absorption. Hole transport was enhanced by thermal annealing to form well-ordered large crystalline domains of PBTTT in the PBTTT:PCBM blend film. The temperature-dependent solubility of PBTTT enabled us to construct the first bilayer bulk-heterojunction devices based on a PBTTT:PCBM (1:2)/MDMO-PPV:[70]PCBM (1:4) active layer. The bilayer device exhibited an extended optical absorption over the solar spectrum. Postannealing the bilayer bulkheterojunction devices yielded a $V_{\text {oc }}$ of $0.59 \mathrm{~V}, J_{\text {sc }}$ values of $10.1-10.7 \mathrm{~mA} / \mathrm{cm}^{2}$, FF of 0.50 , and PCE values of $3.0-3.2 \%$, showing an increased $J_{\mathrm{sc}}$ and PCE by a factor of 2 with respect to their single-layer counterparts (cf. Table 1). It is envisioned that further enhanced photovoltaic performance for the PBTTT solar cells could be achieved by surface functionalization during the device preparation to improve the crystallization of PBTTT as the mobility of PBTTT has been demonstrated to strongly depend on the surface chemistry of the substrate. ${ }^{24}$

Acknowledgment. The authors acknowledge the support from Ohio Department of Development under the 3rd Frontier Program (ODOD RCP-Tech 07-029). We also acknowledge partial support from AFOSR.

\section{References and Notes}

(1) Sariciftci, N. S.; Smilowitz, L.; Heeger, A. J.; Wudl, F. Science 1992, 258, 1474 .

(2) Yu, G.; Gao, J.; Hummelen, J. C.; Wudl, F.; Heeger, A. J. Science 1995, 270, 1789.

(3) Nunzi, J. M. C. R. Physique 2002, 3, 523.

(4) Hoppe, H.; Sariciftci, N. S. J. Mater. Chem. 2004, 19, 1924.

(5) Shaheen, S.; Brabec, C. J.; Sariciftci, N. S.; Padinger, F.; Fromherz, T.; Hummelen, J. C. Appl. Phys. Lett. 2001, 78, 841.

(6) Padinger, F.; Rittberger, R.; Sariciftci, N. S. Adv. Funct. Mater. 2003, 13,85 .

(7) Reyes, R. R.; Kim, K.; Carrol, D. L. Appl. Phvs. Lett. 2005, 87, 083506.

(8) Kim, J.; Kim, S.; Lee, H.; Lee, K.; Ma, W.; Gong, X.; Heeger, A. J. Adv. Mater. 2006, 18, 572.

(9) Wudl, F. Acc. Chem. Res. 1992, 25, 157161.

(10) Zhang, C.; Choi, S.; Haliburton, J.; Cleveland, T.; Li, R.; Sun, S. S.; Ledbetter, A.; Bonner, C. E. Macromolecules 2006, 39, 4317.

(11) Peng, Q.; Park, K.; Lin, T.; Durstock, M.; Dai, L. J. Phys. Chem. $B$ 2008, 112, 2801, and references cited therein.

(12) Hou, J.; Tan, Z.; Yan, Y.; He, Y.; Yang, C.; Li, Y. J. Am. Chem. Soc. 2006, 128, 4911.

(13) Shi, C.; Yao, Y.; Yang, Y.; Pei, Q. J. Am. Chem. Soc. 2006, 128, 8980 .

(14) Pivrikas, A.; Juska, G.; Mozer, A. J.; Scharber, M.; Karlauskas, A.; Sariciftci, N. S.; Stubb, H.; Osterbacka, R. Phys. Rev. Lett. 2005, 94, 176806. 
(15) Bao, Z.; Dodabalapur, A.; Lovinger, A. Appl. Phys. Lett. 1996, $69,4108$.

(16) Sirringhaus, H.; Tessler, N.; Friend, R. H. Science 1998, 280, 1741

(17) Prosa, T. J.; Winokur, M. J.; Moultan, M. M.; Smith, P.; Heeger, A. J. Macromulecules 1992, 25, 4364.

(18) Reyes-Reyes, M.; Kim, K.; Dewald, J.; Lopez-Sandoval, R.; Avadhanula, A.; Curran, S.; Carroll, D. Org. Lett. 2005, 7, 5749.

(19) McCulloch, I.; Heeney, M.; Bailey, C.; Genevicius, K.; MacDonald, I.; Shkunov, M.; Sparrowe, D.; Tierney, S.; Wagner, R.; Zhang, W.; Chabinyc, M. L.; Kline, R. J.; McGehee, M. D.; Toney, M. F. Nat. Mater. 2006, 5,328 .

(20) Chabinyc, M. L.; Toney, M. F.; Kline, R. J.; McCulloch, I.; Heeney, M. J. Am. Chem. Soc. 2007, 129, 3226.

(21) Northrup, J. E. Phys. Rev. B 2007, 76, 245202.

(22) DeLongchamp, D. M.; Kline, R. J.; Lin, E. K.; Fischer, D. A.;

Richter, L. J.; L. A; Lucas, L. A; Heeney, M.; McCulloch, I.; Northrup, J. E. Adv. Mater. 2007, 19, 833.

(23) Lucas, L. A.; DeLongchamp, D. M.; Vogel, B. M.; Lin, E. K.; McCulloch, I.; Heeney, M.; Jabbour, G. E. Appl. Phys. Lett. 2007, 90, 012112 .

(24) Kline, R. J.; DeLongchamp, D. M.; Fischer, D. A.; Lin, E. K.; Heeney, M.; McCulloch, I.; Toney, M. F. Appl. Phys. Lett. 2007, 90, 062117. (25) Dhoot, A. S.; Yuen, J. D.; Heeney, M.; McCulloch, I.; Moses, D.; Heeger, A. J. Proc. Natl. Acad. Sci. U.S.A. 2006, 103, 11834.

(26) Yuen, J. D.; Dhoot, A. S.; Namdas, E. B.; Coates, N. E.; Heeney, M.; McCulloch, I.; Moses, D.; Heeger, A. J. J. Am. Chem. Soc. 2007, 129, 14367.
(27) Hwang, I.-W.; Kim, J. Y.; Cho, S.; Yuen, J.; Coates, N.; Lee, K.; Heeney, M.; McCulloch, I.; Moses, D.; Heeger, A. J. J. Phys. Chem. C 2008, 112, 7853 .

(28) Li, G.; Shrotriya, V.; Huang, J.; Yao, Y.; Moriarty, T.; Emery, K.; Yang, Y. Nat. Mater. 2005, 4, 864.

(29) Sun, Q.; Dai, L.; Zhou, X.; Li, L.; Li, Q. Appl. Phys. Lett. 2007, 91, 253505.

(30) Li, L.; Kang, S.; Harden, J.; Sun, Q.; Dai, L.; Jakli, A.; Kumar, S.; Li, Q. Liquid Cryst. 2007, 35, 233.

(31) Li, Y. F.; Cao, Y.; Gao, J.; Wang, D. L.; Yu, G.; Heeger, A. J. Synth. Met. 1999, 99, 243. According to the equations HOMO $=-\left(E_{\mathrm{ox}}{ }^{\prime}+\right.$ 4.39) $\mathrm{eV}$ and LUMO $=-\left(E_{\mathrm{red}}{ }^{\prime}+4.39\right) \mathrm{eV}$, by assuming that the formal potential of $\mathrm{Fc} / \mathrm{Fc}^{+}$corresponds to a vacuum energy level of $-4.8 \mathrm{eV}$.

(32) Kline, R. J. M. D.; McGehee, M. D.; Toney, M. F. Nat. Mater. 2006, 222.

(33) Hoppe, H.; Niggemann, M.; Winder, C.; Kraut, J.; Hiesgh, R.; Hinsch, A.; Meissner, D.; Sariciftci, N. S. Adv. Funct. Mater. 2004, 14, 1005 .

(34) Organic Photovoltaics echanis, aterials, and Devices; Sun, S.-S., Sariciftci, N. S., Eds.; CRC Press: Boca Raton, FL, 2005.

(35) Ahn, T.; Sein Holta, H. L. Appl. Phys. Lett. 2002, 80, 392.

(36) Wienk, M.; Kroon, J. M.; Verhees, W. J. H.; Krol, J.; Hummelen,

J. C.; Van Haal, P.; Jassen, R. A. J. Angew. Chem., Int. Ed. 2003, 42, 3371.

(37) Gunes, S.; Neugebauer, H.; Sariciftci, N. S. Chem. Rev. 2007, 107, 1324

JP900241R 